\title{
Macroeconomic Effects of Selective Public Employment and Wage Subsidies
}

DireCt JOB CREATION and selective wage subsidies are policies designed to alter the mix of employment in favor of workers who, in the normal course of economic events, experience high rates of unemployment. As instruments of macroeconomic policy, these measures are intended to mitigate the conflict between society's goals for unemployment and inflation. The hope is to "cheat the Phillips curve." For the short run, as in the current cyclical recovery, this means to diminish the inflationary consequences of higher rates of employment. For the long run, it means to diminish the natural rate of unemployment-or, to use a more neutral term, the minimal nonaccelerating-inflation rate of unemployment

Note: This paper presents the analytical framework for the principal arguments, and some related empirical evidence, underlying a paper, "Direct Job Creation, Inflation, and Unemployment," delivered by the authors at the Conference on Direct Job Creation sponsored by the Brookings Institution and the Institute for Research on Poverty, held in Washington in April 1977. The conference paper, as revised, will be published in a Brookings volume devoted to the papers presented at the conference.

We would like to thank participants in the conference for helpful comments, and to acknowledge with gratitude the excellent research assistance of Richard Kolsky, Hiroshi Yoshikawa, and David Coppock. We are grateful also for the financial support provided by the institutions sponsoring the conference and by the National Science Foundation. 
(NAIRU). In general, the purpose is to allow standard fiscal and monetary policy to achieve more satisfactory joint paths of output, employment, and prices.

The basic strategy is simple: Shift labor demand to types of workers who are-because of high unemployment, weak bargaining power, rigid wages, or other characteristics-on relatively flat Phillips curves. Let the government hire, or induce other employers to hire, workers whose unemployment does little or nothing to restrain the advance of wage costs in the aggregate. The idea is appealing, and our purpose is to examine it systematically. Most of our discussion concerns the long run-the possibility of reducing the NAIRU-because it is in that context that the strategy is most likely to encounter complications and pitfalls.

For the strategy to have a chance, selective eligibility is essential. Public employment opportunities or wage subsidies must be confined to workers whose supply and demand have relatively little to do with economy-wide inflation. From a macroeconomic viewpoint, this is the reason for eligibility criteria whose rationales may vary greatly: low income, low wage, welfare dependency, previous unemployment, residence in a labor surplus area, youth. Open-ended "employer of last resort" programs and general employment subsidies would not carry out the macroeconomic strategy to which our paper is directed.

We will present two analyses of the way selective employment policies may work. The first is an aggregative model of frictional unemployment and its possible reduction. The second is an explicitly disaggregated model of labor markets, in which the power of selective employment policies comes from exploiting differences among markets in wage responses.

\section{Reducing Frictional Unemployment}

Excess demand in any labor market is measured conceptually by the algebraic excess of jobs over the labor force, or of job vacancies over the unemployed. For given excess demand, both vacancies and unemployment may be high, or they may be low. Unemployment matched by simultaneous vacancies is frictional unemployment. It is a reasonable assumption that inflationary pressure on wages is proportional to excess demand, or depends separately on its components, vacancies and unemployment. If so, both the inflation-unemployment tradeoff and the NAIRU can be 
improved by reductions of frictional unemployment. Some labor-market policies-retraining, relocating, and more efficient exchanges of information-are specifically designed to place unemployed workers in existing vacancies, or to facilitate job searches and shifts without intervening spells of unemployment.

These aims are not central features of direct job creation. Nevertheless, such programs may indirectly diminish frictional unemployment. Job vacancies connected with direct job creation should be minimal, while the program itself could be a channel for routing unemployed workers to vacancies in the private sector as long as the wages and duration of the jobs did not reduce incentives to look for alternatives. Their availability may brake market wage increases nearly as much as if they were actually unemployed.

Wage subsidies per se do not promise the same reductions in frictional unemployment. If the subsidy for employing an eligible worker is permanent and the wage is uncontrolled, search behavior will not be modified. The mechanism by which wage subsidies could be effective is described by the second model below.

The first model is as follows: ${ }^{1}$

$$
U L(J, x)-L(J, x)+N(J, x)=0, \quad 0<L_{J}<N_{J}<1 .
$$

Here $U$ is the unemployment rate; $L$ is the labor force, a function of the number of jobs (or slots), $J$, and of a policy parameter, $x$; and $N$ is employment, a function of the same two variables.

$$
V J-J+N(J, x)=0 .
$$

The vacancy rate, $V$, is measured relative to the number of jobs:

$$
\dot{W}=f(U, V, x)+\dot{W}^{s}, f_{U}<0, f_{V}>0 .
$$

Here, $\dot{W}$ is the proportional rate of wage inflation $(1 / W \cdot d W / d t)$, and depends on built-in or expected inflation, $\dot{W}^{e}$, and on the vacancy and unemployment rates. The NAIRU condition is

$$
f(U, V, x)=0 .
$$

1. This is an elaboration of a model one of us presented previously to serve as an organizing framework for examining ways in which labor-market policies, direct job creation and others, could alter the inflation-unemployment tradeoff and the NAIRU. See the comment by James Tobin (on Michael Wiseman, "Public Employment as Fiscal Policy") in BPEA, 1:1976, pp. 107-10. 
For long-run equilibrium the three equations 1,2 , and 4 determine $U, V$, and $J$ as a function of the policy variable, $x$. The number of jobs, $J$, is directly related to aggregate real demand, and thus to monetary and fiscal policies that affect it. Nevertheless, $J$ is an endogenous variable in long-run analysis, in the sense that the monetary and fiscal policymakers seek the maximum $J$ consistent with nonaccelerating inflation.

The solution of the system gives the NAIRU, $\bar{U}$, and

$$
\begin{array}{r}
\Delta \frac{d U}{d x}=-N_{x} f_{V}\left[1-V-L_{J}(1-U)\right]+ \\
L_{x}(1-U) f_{V}\left(1-V-N_{J}\right) \\
-f_{x} J\left[L_{J}(1-U)-N_{J}\right],
\end{array}
$$

where

$$
\Delta=L f_{V}\left(1-V-N_{J}\right)+J f_{U}\left[L_{J}(1-U)-N_{J}\right] .
$$

Assume that, with unchanged policy $x$, increasing $J$ raises the vacancy rate $\left(1-V>N_{J}\right)$ and decreases the unemployment rate- $L_{J}(1-U)$ $<N_{J}$. Equation 5 shows that a policy $x$ will tend to reduce the NAIRU if:

(a) $N_{x}>0$; that is, the policy diminishes the slippage between jobs and employment. This reduction in the vacancy content of jobs works only if $f_{V}>0$-that is, if the vacancy rate, as well as the unemployment rate, affects the rate of wage inflation.

(b) $L_{x}<0$; that is, the policy diminishes the endogenous response of the labor force to the number of jobs. This also works only if $f_{V}>0$.

(c) $f_{x}<0$; that is, the policy diminishes wage inflation for a given combination of vacancies and unemployment.

The short-run Phillips tradeoff is $(d \dot{W} / d J) /(d U / d J)$. Using equations 1,2 , and 3, and taking $\dot{W}^{e}$ as given,

$$
\frac{d \dot{W} / d J}{d U / d J}=\frac{f_{V}\left(1-V-N_{J}\right) L}{\left[L_{J}(1-U)-N_{J}\right] J}+f_{U}
$$

Policy will make the Phillips curve flatter if (a) it raises $N_{J}$, (b) it lowers $L$ relative to $J$ or reduces $L_{J}$, (c) it lowers $f_{V}$ or the absolute size of $f_{U}$ or both. These three points correspond to the three points for NAIRU. As in that case, points (a) and (b) apply only if $f_{V}>0$.

This model is illustrated in figure 1 , in which the number of jobs $J$ is measured horizontally, the labor force $L$ and employment $N$, vertically. The curve $L(J)$ indicates the dependence of the labor force on job availability; its positive slope represents the well-known fact that labor-force participation is responsive to job opportunities. The curve $N(J)$ represents the transformation of jobs into actual employment. Be- 
Figure 1. Effects of Labor-Market Policy in Reducing Frictional Unemployment

Labor force, $L$

Employment, $N$

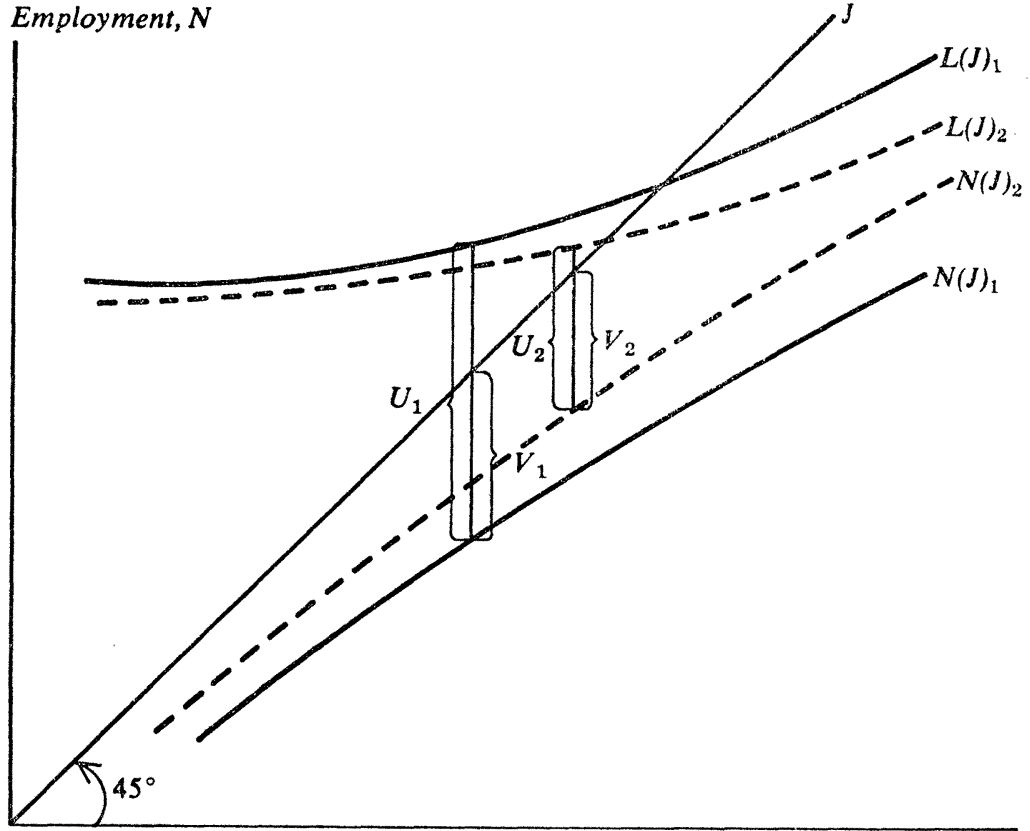

Number of jobs, $J$

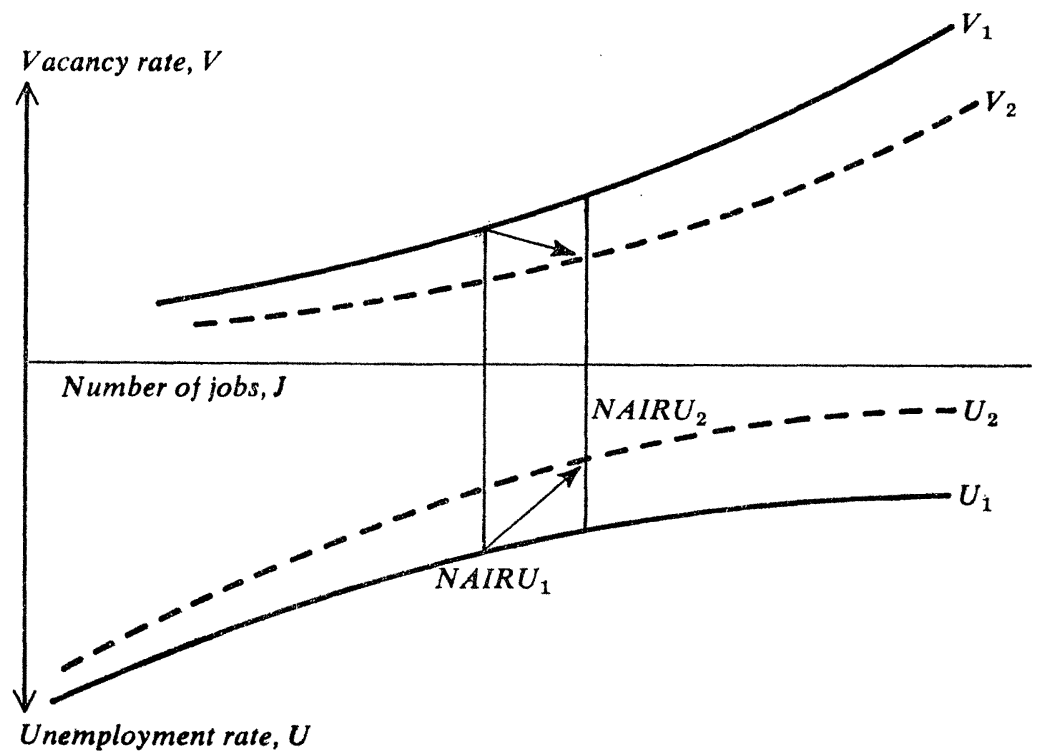


cause of "friction," the transformation is imperfect. The vertical shortfall of $N(J)$ from the $45^{\circ}$ reference line $J$ indicates the number of vacancies. Unemployment is the vertical distance $L-N$. In the lower panel, the vacancy rate, relative to jobs, and the unemployment rate, relative to the labor force, are shown. One pair of these rates is consistent with stable wage inflation, and this determines the NAIRU and corresponding jobs, vacancies, employment, and labor force.

The dashed lines represent some favorable shifts due to policy actions, perhaps direct job creation. As indicated, these permit increases in the long-run equilibrium levels of jobs and employment, and a reduction in the NAIRU. The gains arise from reducing the vacancy rate corresponding to any given unemployment rate. The necessary assumption is that vacancies have an independent inflationary effect on wages. On this assumption, a policy that will reduce the vacancy slippage in $N(J)$ or reduce the induced labor-supply response in $L(J)$ will diminish the NAIRU. Such a policy will also flatten the short-run Phillips curve and improve the trade off.

Direct job creation could have both effects. The key points are the limited eligibility of workers for the program and control of the wage rates. Vacancies, if they exist, would not have the normal effects on wages, and would not be a reason for job-seeking workers to decline other jobs at going wage rates. Similarly, the selective eligibility criteria could hold below normal the response of entrants or reentrants into the labor force to the creation of new jobs.

The third possible policy effect is reduction in the wage pressure associated with a given state of the labor market. Direct job creation could contribute to this result insofar as employees under the program continued to look for and be available for other jobs in nearly the same degree as if they were unemployed. Keeping wage rates for the program below the market, limiting tenure in the jobs, and providing placement service would encourage such behavior.

\section{Segmented Labor Markets and the NAIRU}

This section explores the conditions under which direct job creation could exploit differences among labor markets in order to reduce the NAIRU. In the next section the same apparatus is used to analyze a wage subsidy. 
Unemployment is measured in persons. But persons differ widely in the effective labor input they provide per hour. A natural first approximation is that effective labor is proportional to the hourly wage. At the margin, substitution of two workers at $\$ 2.50$ an hour for one worth $\$ 5.00$ an hour leaves effective labor input unchanged, and presumably gross national product as well. However, it increases employment and reduces unemployment, measured in persons (though the unemployment reduction may be partially offset by induced labor-force entry).

Suppose that the true aggregate Phillips curve relates inflation of the wage per effective worker to the rate of unemployment per effective worker. A low-wage worker has a relatively low weight in the wage index, and his unemployment exerts correspondingly little restraint on increases in the index. The NAIRU would be determined as a certain amount of wage-weighted unemployment. The equilibrium unemployment count could vary, but not effective labor input or GNP. ${ }^{2}$

Substitutions of low-wage for high-wage workers, diminishing the number of persons unemployed, might be regarded as socially desirable even though total output is not increased. The social disutility of unemployment may depend in part on the number of persons affected, not just on the sum of labor resources wasted. The substitution of low-wage for high-wage employment may result in a fairer allocation of the unemployment required for restraining inflation. The formation of human capital via work experience, an output not included in GNP, may be greater the more persons are employed. Some of these considerations apply also to other proposals for sharing work and unemployment-for example, forced reductions in hours of work.

As a numerical illustration, consider a two-way split of the labor force into adults and teenagers. The ratio of an individual adult to an individual teenager in Perry's wage-weighted unemployment measure is 3.05..$^{3}$ Assuming that substitution in production can be made at this ratio over a relevant range, employment of one hundred teenagers would displace

2. George L. Perry estimated such an equation in "Changing Labor Markets and Inflation," $B P E A, 3: 1970$, pp. 411-41. The unemployed were classified by demographic groups defined by age and sex. Smaller wage weights per person were given to unemployed teenagers and females than to adult males. Thus a redistribution of unemployment at the expense of high-wage workers would lower the NAIRU in persons, but not lower the NAIRU in weighted persons or raise GNP.

3. This was computed from Perry's "Changing Labor Markets" (p. 440). Since Perry has finer disaggregation, his weights were reaggregated for the two-way classification. 
thirty-three adults. The weighted unemployment rate and GNP would be unchanged, but the unemployment count would be down by sixtyseven." This calculation will be a convenient reference point for further illustrative estimates, using the same two-way break of the labor force.

The aggregate model, however, raises troubling questions. If the labor inputs of different workers are perfectly substitutable at prevailing wages, what determines the distribution of employment? Why are there such great differences in unemployment rates among the demographic groups? If the various types of workers are not good substitutes, what determines their relative wages and their differential impacts on average wage inflation?

The most appropriate model to deal with these questions seems to us to be one that (a) permits some flexibility in relative wages and determines equilibrium relative wages for the long run; (b) allows for some substitution in production among workers of different types; and (c) explains the determination of wages in different markets. Continuing illustratively to use two demographic groups, adults (group 1) and teenagers (group 2), let $L_{1}$ and $L_{2}$ be the sizes of the labor force of the two groups, and $\alpha_{1}$ and $\alpha_{2}$ the shares $\left[\alpha_{i}=L_{i} /\left(L_{1}+L_{2}\right)\right] .{ }^{5}$ The $L$ s are assumed constant for the present, an important assumption discussed below. Two wage rates call for two wage equations. Our specification is

$$
\begin{gathered}
\dot{W}_{1}=f^{1}\left(\alpha_{1} U_{1}, \alpha_{2} U_{2},-\ln R\right)+h_{1}^{1} \dot{W}_{:}^{e}+h_{2}^{1} \dot{W}_{2}^{e}, \\
f_{1}^{1}<f_{2}^{1}<0, f_{3}^{1}>0 ; h_{1}^{1}, h_{2}^{1} \geqq 0, h_{1}^{1}+h_{1}^{2}=1 ; \\
\dot{W}_{2}=f^{2}\left(\alpha_{1} U_{1}, \alpha_{2} U_{2}, \ln R\right)+h_{1}^{2} \dot{W}_{1}^{e}+h_{2}^{2} \dot{W}_{2}^{e}, \\
f_{2}^{2}<f_{1}^{2}<0, f_{3}^{2}>0 ; h_{1}^{2}, h_{2}^{2} \geqq 0, h_{1}^{2}+h_{2}^{2}=1 .
\end{gathered}
$$

Both unemployment rates appear in each equation. The two types of workers are in some degree substitutes, and unemployment of each type restrains both wage rates. However, the "own" effects should be stronger

4. This example does not take account of changes in labor-force participation. A reduction in the rate of unemployment of teenagers might encourage more of them to enter the labor force. To some extent this would be offset-in its impact on the unemployment rate-by a reduction in adult participation.

5 . Other divisions of the labor force, with $n$ groups rather than two, could be handled by the same type of analysis. A more realistic formulation would be to distinguish $m$ labor markets-say, industries-in which distinct wages are determined. The $n$ types of labor would participate in varying degrees in each of the markets. In the illustrative two-group model, however, labor markets and wage rates are identified with the two demographic groups. 
- that is, each wage rate is more sensitive to unemployment of the type of labor in that market. The unemployment rates are weighted by shares in the labor force; the arguments $\alpha_{1} U_{1}$ and $\alpha_{2} U_{2}$ are proportional to the number of persons of each type unemployed. The ratio of the levels of the two wage rates, $W_{1} / W_{2}$, is expressed as $R$. The assumption is that each sectoral wage rises faster, other things equal, when it is low relative to the other wage. The $h$ functions are the feedback or expectational terms. The specification says that an equal increase in the two expected rates of wage inflation will raise both actual rates of wage increase $\dot{W}_{i}$ one for one. However, the two expected rates may, if they differ, have different effects in the two markets.

Inclusion of $R$ in the sectoral Phillips curves requires further explanation. Sectoral Phillips curves are "reduced form" equations that reflect forces from both sides of the labor market-firms and workers. Behavior on both sides suggests that the relative wage $R=W_{1} / W_{2}$ should be an argument in $f^{1}$ and $f^{2}$. First, employers pay attention to relative wage levels when establishing their wage offers to the two types of labor. ${ }^{6}$ Second, and perhaps more compelling, the job-search and turnover behavior of teenagers or other secondary workers will be affected by their relative wage. At the point $f^{2}=0$, the excess supply (unemployment) of group 2 workers balances the inflation pressure from excess demand (vacancies). Much of the problem of teenage unemployment, it is often observed, comes from dissatisfaction with the available jobs, a gap between expectations or aspirations and the realities of miserable wages and working conditions. One consequence is the high turnover among teenagers. The $f^{2}=0$ equilibrium, therefore, occurs with very high $U_{2}$, because an individual unemployed teenager does not exert much excess-supply pressure on the market. If the relative position of teenagers were improved-in practice, by improving working conditions as well as by raising wageseach unemployed teenager would exert more effective pressure, and the equilibrium would involve less dissatisfaction and lower turnover. In short, for a given $W_{2}$ the required $U_{2}$ is smaller when $R$ is lower-that is, when the relative position of teenagers is better. Third, when adult workers are bargaining for wage increases they, as well as their employers, consider

6. The relative wage is, of course, relevant for employers' demand for labor of the two types. This effect is in the labor-demand functions implicit in equation 17 below. The behavior of employers embedded in the $f$ functions has to do with hiring and turnover strategy. 
the potential for substituting secondary workers. When the relative wage is high, group 1 workers may moderate their own wage demands or even bargain for higher group 2 wages in order to protect their own jobs. ${ }^{7}$ Longrun equilibrium requires that the relative wage $R$ be constant and that expectations are realized: $\dot{W}_{1}=\dot{W}_{2}=\dot{W}_{1}^{e}=\dot{W}_{2}^{e}$. Thus the NAIRU condition is that $f^{1}=f^{2}=0 .{ }^{8}$ The aggregate NAIRU in persons is $\alpha_{1} U_{1}$ $+\alpha_{2} U_{2}$. The aggregate NAIRU in wage-weighted persons is $\bar{R} \alpha_{1} U_{1}$ $+\alpha_{2} U_{2}$, where $\bar{R}$ is a reference relative wage.

If the relative wage, $R$, is omitted from equations 7 , they determine unique values of both unemployment rates in the NAIRU equilibrium. Specifically, they determine a pair of unemployment rates $\left(\alpha_{1} U_{1}, \alpha_{2} U_{2}\right)$ at which $\dot{W}_{1}=\dot{W}_{2}=\dot{W}_{1}^{e}=\dot{W}_{2}^{e} \cdot{ }^{9}$ If this were the correct specification, direct job creation would be unavailing in the long run. Hiring teenagers in public jobs would lower their unemployment rate in the short run, drive up their relative wage, and lead to the substitution of adults for teenagers in private employment. This process, plus the necessary policy adjustment of output to avoid wage acceleration, would not stop until a number of teenagers equal to the number employed in public jobs had been displaced from private employment.

With $R$ included, the two equations $f^{1}=0, f^{2}=0$ determine $\alpha_{1} U_{1}$ and $\alpha_{2} U_{2}$, each as a function of $R$ :

$$
\begin{aligned}
& \alpha_{1} U_{1}=s^{1}(R), s_{R}^{1}<0, \\
& \alpha_{2} U_{2}=s^{2}(R), s_{R}^{2}>0 .
\end{aligned}
$$

Type 1 unemployment falls with $R$; a high $W_{1}$ relative to $W_{2}$ dampens the pressure for wage increases and thus allows a lower unemployment rate. For like reasons, type 2 unemployment rises with $R$. In figure 2 the locus of combinations $\left(\alpha_{1} L U_{1}, \alpha_{2} L U_{2}\right)$ that meet the NAIRU condition is shown graphically as the curve marked $f^{1}=f^{2}=0$ in the upper right.

7. Some analysis of behavior of this kind appears in Martin Neil Baily, "Contract Theory and the Moderation of Inflation by Recession and by Controls," $B P E A$, 3:1976, pp. 585-622.

8. An expected-price feedback formulation would imply that the $f \mathrm{~s}$ are equal to the normal growth of labor productivity. We abstract from changes in raw-material prices, taxes, and other external price determinants, so the difference between the two formulations is not significant.

9. If the cross-effects are ignored, the monotonicity of the two fs ensures that there are uniquely determined values of $\alpha_{1} U_{1}$ and $\alpha_{2} U_{2}$. Allowing for the cross-effects does open the technical possibility of multiple equilibria, but this possibility does not look very interesting as an avenue by which to lower the NAIRU. 


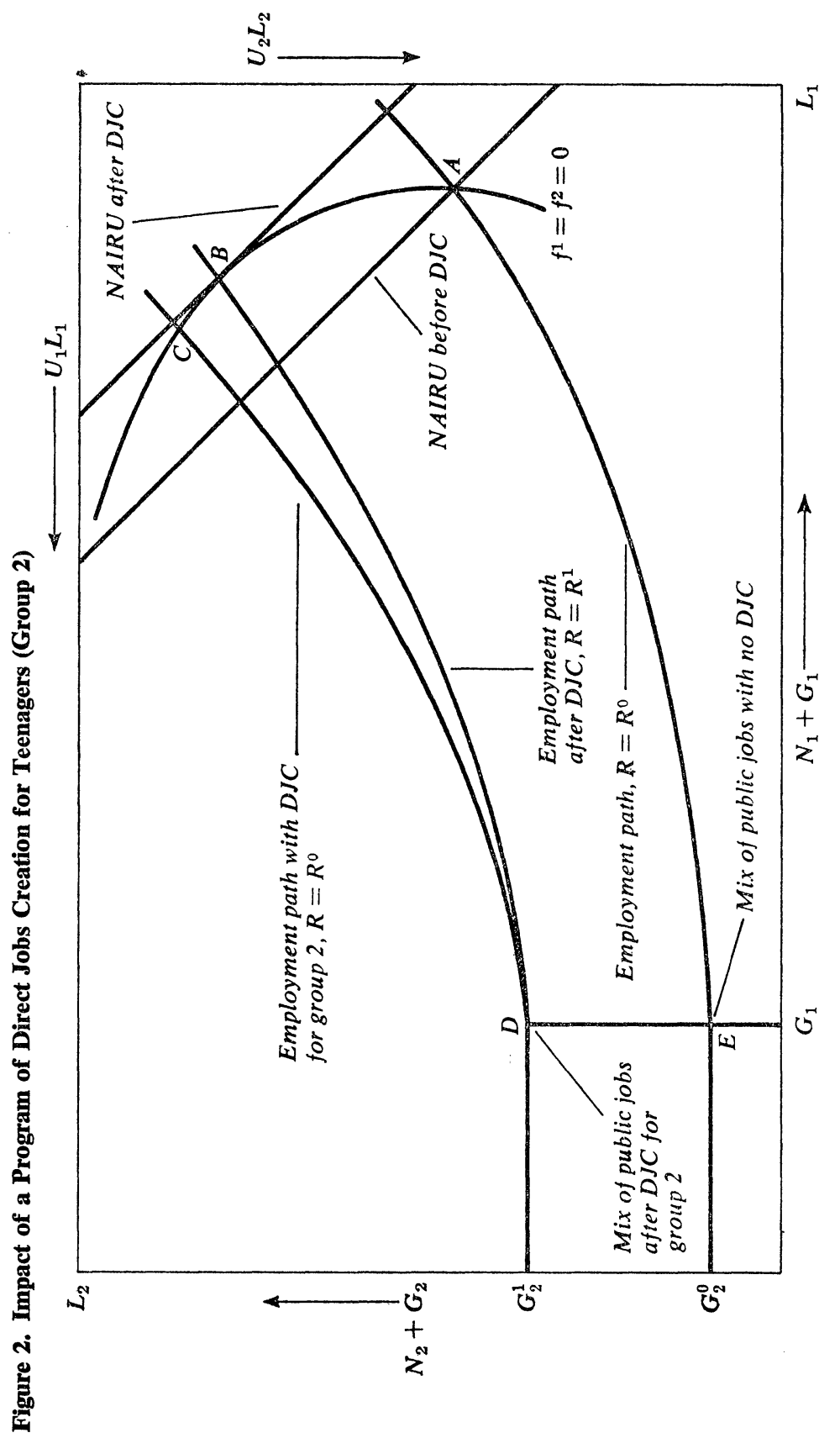


The slope of this NAIRU locus $\left[\partial\left(\alpha_{2} U_{2}\right)\right] /\left[\partial\left(\alpha_{1} U_{1}\right)\right]$ is $s_{R}^{2} / s_{R}^{1}$ and is negative. Movement down the locus, as oriented in figure 2 , is associated with increases in $R .^{10}$

The steeper the locus is at the point the economy reaches in the absence of policy-for example, $A$ in figure 2-the greater is the potential reduction in aggregate unemployment from policies varying $U_{1}$ and $U_{2}$ along the locus. The total unemployment count is $L_{1} U_{1}+L_{2} U_{2}$, and points of equal count, therefore, lie along straight lines of slope -1 in figure 2. At point $A$, the locus is steeper than such a line, indicating the potential for reducing the number of persons unemployed by moving up the locus. ${ }^{11}$

Aggregate unemployment in "teenage equivalent" units, with persons weighted in proportion to their wage rates at point $A$, is $\bar{R} L_{1} U_{1}+L_{2} U_{2}$. Points of equal wage-weighted unemployment lie along lines of slope $-\bar{R}$, steeper than $45^{\circ}$. Only if the slope of the locus is steeper than the relative wage is it possible to reduce wage-weighted unemployment and to increase GNP (assuming that relative wages match relative marginal products).

We will now show that, under plausible assumptions, the slope of the

10.

$$
\begin{aligned}
s_{R}^{1} & =\frac{1}{R \Delta}\left(f_{3}^{1} f_{2}^{2}+f_{3}^{2} f_{2}^{1}\right) ; \\
s_{R}^{2} & =\frac{1}{R \Delta}\left(-f_{3}^{2} f_{1}^{1}-f_{3}^{1} f_{1}^{2}\right) ; \\
\Delta & =f_{1}^{1} f_{2}^{2}-f_{2}^{1} f_{1}^{2} .
\end{aligned}
$$

$\Delta$ is positive by assumption of dominance of "own" effects. The signs of $s_{R}^{1}$ and $s_{R}^{2}$ asserted in the text follow from the other assumptions in equations 7 .

11. The locus is shown as concave from below. The concavity is not necessary for the results derived here; it is only necessary that the locus be steeper than the $45^{\circ}$ line at point $A$. Concavity is extremely plausible, however. It suggests decreasing returns to successive application of direct job creation in reducing the NAIRU. The diagram suggests that there is, in fact, a limit to the process-shown as the minimum NAIRU. According to note 10 , the locus slope is

$$
-\frac{f_{3}^{2} f_{1}^{1}+f_{3}^{1} f_{1}^{2}}{f_{3}^{1} f_{2}^{2}+f_{3}^{2} f_{2}^{1}}
$$

As $U_{1}$ increases, $U_{2}$ decreases, and $R$ falls, what happens to the value of this slope? To justify the convex locus shown in figure 2 , it must fall. From the curvature of Phillips curves, $\left|f_{1}^{1}\right|$ falls and $\left|f_{2}^{2}\right|$ rises; these "own" effects tend to flatten the locus. The decline in $R$ would be expected, if anything, to raise $f_{3}^{1}$ and lower $f_{3}^{2}$, reinforcing the "own" effects. The cross terms in the numerator and denominator work the other way, but seem likely to be weaker. 
locus is likely to be steeper than the relative wage. To simplify the exposition, we shall ignore the cross-effects in 7 of one group's unemployment rate on the other's rate of wage increase, and take the functions to be linear in $R$ and in the reciprocal of unemployment. Thus:

$$
\begin{aligned}
& \dot{W}_{1}=a_{1}+\frac{b_{1}}{U_{1}}-c_{1} R+\text { feedback terms } \\
& \dot{W}_{2}=a_{2}+\frac{b_{2}}{U_{2}}+c_{2} R+\text { feedback terms }
\end{aligned}
$$

Each of these equations defines a family of conventional, sectoral Phillips curves. The higher the value of $R$, the lower the position of the particular group 1 curve that is relevant and the higher the position of the relevant group 2 curve.

Moreover, each equation implies a tradeoff between $R$ and the "own" unemployment rate consistent with equilibrium:

$$
\begin{aligned}
& \left(\frac{-b_{1}}{U_{1}^{2}}\right) d U_{1}-c_{1} d R=0 ; \\
& \left(\frac{-b_{2}}{U_{2}^{2}}\right) d U_{2}+c_{2} d R=0
\end{aligned}
$$

Directly from 10 ,

$$
\frac{d U_{1}}{d R}=\frac{-c_{1} U_{1}^{2}}{b_{1}} ; \quad \frac{d U_{2}}{d R}=\frac{c_{2} U_{2}^{2}}{b_{2}} .
$$

Now the slope of the locus of equilibria in figure 2 can be written as

$$
\frac{L_{2} d U_{2}}{L_{1} d U_{1}}=\frac{-L_{2} c_{2} U_{2}^{2} b_{1}}{L_{1} c_{1} U_{1}^{2} b_{2}}
$$

Next, for the present assume that changes in $R$ do not alter aggregate inflation; that is, the dollar value of the reduced wage increase in group 1 from a higher $R$ is exactly offset by increased wages in group 2 . Then, $c_{1} N_{1} W_{1}=c_{2} N_{2} W_{2}$, or

$$
\frac{c_{2}}{c_{1}}=\frac{N_{1} W_{1}}{N_{2} W_{2}}=\left(\frac{N_{1}}{N_{2}}\right) R
$$

Using equation 13 in 12 and simplifying leads to another expression for the locus slope:

$$
\frac{L_{2} d U_{2}}{L_{1} d U_{1}}=-R\left(\frac{b_{1}\left(1-U_{1}\right) U_{2}^{2}}{b_{2}\left(1-U_{2}\right) U_{1}^{2}}\right)
$$


If the fraction that multiplies $R$ on the right side of 14 is unity, then any movement along the locus simply changes the number of unemployed teenagers by $R$ times the change (in the opposite direction) in the number of unemployed adults. In that event, no improvements in wageweighted unemployment or in GNP are possible through policies that alter the mix of unemployment, although a reduction of the head-count NAIRU is possible.

There are analytical reasons for thinking this outcome is too pessimistic. To accept it is tantamount to asserting that the labor market is operating efficiently - one can redistribute unemployment at the margin, but one cannot gain anything overall. Not only the minimum wage, but institutional factors such as union hiring rules, employer discrimination, inadequate information, geographic separation of jobs and inner-city youths-and perhaps more diffuse sociological factors such as the legacy of alienation and disillusionment of younger workers-all surely contribute to a labor market that is not efficient. Intervention in this labor market, whether by direct job creation or by a wage subsidy, in favor of disadvantaged workers, whether teenagers or some other group, should do better than the reference outcome.

There is, moreover, crude empirical support for the same conclusion, stemming from equation 14. In 1974, the unemployment rates for adults and teenagers were 4.5 and 16 percent, respectively. For the expression that multiplies $R$ to be unity with those sharply contrasting values of $U_{1}$ and $U_{2}$, the ratio of $b_{2}$ to $b_{1}$ would have to be 14.4 . At the same unemployment rate for both groups, the sectoral Phillips curve for teenagers would have to be more than fourteen times as steep as that for adults! Any ratio of slopes below that would mean that a lowering of $U_{2}$, with its inflationary effect just neutralized by a rise of $U_{1}$, would lead to more GNP as well as a cut in the overall head count of unemployment. To be sure, there are reasons to believe that $b_{2}$ exceeds $b_{1}$ by some margin. It would be extreme to suppose that the Phillips curve for teenagers is simply a vertical displacement of the adult curve. Entry, reentry, and search are much more important for teenagers than for adults. But a ratio of 14 to 1 seems implausible. We feel justified in suggesting that the slope of the locus may well be above the reference value of $R$.

Adding the impact of cross-effects should steepen the locus slope further. The impact of teenage unemployment on prime-wage inflation 
$\left(f_{2}^{1}\right)$ is negligible compared with the effect of adult unemployment on secondary-wage inflation $\left(f_{2}^{2}\right)$.

So far our model explains (1) how, via a decline in $R$, the adult wage relative to the teenage wage, it may be possible to reduce teenage unemployment while increasing adult unemployment; (2) how such a change in the mix may reduce aggregate unemployment counted in persons; and (3) how it may even diminish wage-weighted unemployment. The argument refers to a "long-run" equilibrium, to rates of unemployment that meet the conditions for the NAIRU, and to shifts of that equilibrium when the composition of labor demand is shifted in favor of teenagers.

However, we have not so far taken account of endogenous effects on labor demand resulting from the adjustment of relative wages. The decline in $R$ is crucial to the mechanism described here, but it should induce substitution of adult workers for teenage workers in private employment, diminishing the effectiveness of direct job creation. The offset is depicted qualitatively in figure 2 . In the absence of direct job creation the expansion path of private employment is $E A$. This describes the mix of employment of the two types of labor that employers will offer at a given relative wage $R^{0}$, specifically the relative wage that corresponds to point $A$ on the NAIRU locus $C B A$. Path $D C$ is the same, displaced vertically by the number of public jobs provided for type 2 workers. However, on the NAIRU locus, $C$ requires a lower $R$ than $R^{0}$. Unless the proportions in which workers are used is insensitive to the relative wage, the expansion path will shift against teenagers, rotating clockwise around point $D$. A new equilibrium - for example, $B$-will be associated with a lower $R$ than the initial equilibrium $A$, and with lower private employment of both teenagers and adults. Private employment will be lower for both groups--this would also be true in the absence of substitution, as at point $C$-and especially for teenagers.

An extreme case, the polar opposite of zero substitution in private employment, is that the two types of workers are perfect substitutes, and that the relative wage $R$ indicates the constant rate of substitution. If $R^{0}$, corresponding to point $A$, is that rate, then point $A$ is the only possible equilibrium, whether public jobs are at $E$ or at $D$. In this case, direct job creation will be fruitless; an equal number of teenagers will lose private jobs.

To analyze substitution formally, suppose that private output $Q$ is 
produced by the two types of workers, along with capital and other factors, assumed constant. The production function $Q\left(N_{1}, N_{2}\right)$ has diminishing returns to scale; $N_{1}$ and $N_{2}$ represent employment of the two types of workers:

$$
\begin{aligned}
& N_{1}=L_{1}-G_{1}-U_{1} L_{1}=L_{1}-G_{1}-s^{1}(R) L, \\
& N_{2}=L_{2}-G_{2}-U_{2} L_{2}=L_{2}-G_{2}-s^{2}(R) L .
\end{aligned}
$$

Here $G_{1}$ and $G_{2}$ are the numbers of workers of the two types in government jobs. From equation $9,\left(L_{i} / L\right) U_{i}=s^{i}(R)$ in the NAIRU equilibrium. The following system of equilibrium equations determines $Q ; w_{2}$, the real wage of group 2 workers; and $R w_{2}$, the real wage of group 1 workers, all as functions of the policy variables $G_{1}$ and $G_{2}$. Private output $Q$ is a variable in the sense that, whether by demand-management policy or by price and wage flexibility, $Q$ adjusts to the NAIRU level in the long run. ${ }^{12}$

$$
\begin{aligned}
Q & =Q\left[L_{1}-G_{1}-s^{1}(R) L, L_{2}-G_{2}-s^{2}(R) L\right], Q_{1}, Q_{2}>0 ; \\
R w_{2} & =Q_{1}\left[L_{1}-G_{1}-s^{1}(R) L, L_{2}-G_{2}-s^{2}(R) L\right], Q_{11} \leqq 0 \\
w_{2} & =Q_{2}\left[L_{1}-G_{1}-s^{1}(R) L, L_{2}-G_{2}-s^{2}(R) L\right], Q_{22} \leqq 0 .
\end{aligned}
$$

The second and third equations set each wage equal to the marginal product of labor.

Consider variation of $G_{2}$ by direct job creation:

$$
\left(\begin{array}{ccc}
1 & Q_{1} s_{R}^{1} L+Q_{2} s_{R}^{2} L & 0 \\
0 & Q_{11} s_{R}^{1} L+Q_{12} s_{R}^{2} L+w_{2} & R \\
0 & Q_{21} s_{R}^{1} L+Q_{22} s_{R}^{2} L & 1
\end{array}\right)\left(\begin{array}{l}
\partial Q / \partial G_{2} \\
\partial R / \partial G_{2} \\
\partial w_{2} / \partial G_{2}
\end{array}\right)=\left(\begin{array}{c}
-Q_{2} \\
-Q_{12} \\
-Q_{22}
\end{array}\right)
$$

Recall that $s_{R}^{1}<0, s_{R}^{2}>0$. If the two kinds of labor were perfect substitutes at the relative wage $R$, then an addition of $R$ units of type 2 labor would have the same effects as that of one unit of type 1. Adding to $N_{1}$ reduces $Q_{1}$ at the rate $Q_{11}$; hence adding to $N_{2}$ would reduce $Q_{1}$ at the rate $Q_{11} / R$. If the substitution is less than perfect, $Q_{12}$ will exceed, algebraically, $Q_{11} / R$. The assumption of imperfect substitution- $R Q_{12}-Q_{11}$

12. There is no explicit modeling of the determination of the general price level. It is simply assumed that in any steady state the price level increases at the same rate as the two wage rates (we have abstracted from productivity change). The comparative-statics analysis says that the price level will in the long run adjust so that the two real wages rates $w_{2}$ and $R w_{2}$ satisfy equation 16 . 
$>0$ and $R Q_{22}-Q_{12}<0$ - guarantees that the determinant $\Delta$ of the Jacobian in equation 12 is positive. Also

$$
\begin{aligned}
& \frac{\partial Q}{\partial G_{2}}=-w_{2}+\frac{w_{2}}{\Delta} L\left(R s_{R}^{1}+s_{R}^{2}\right)\left(Q_{12}-R Q_{22}\right) ; \\
& \frac{\partial R}{\partial G_{2}}=\frac{1}{\Delta}\left(R Q_{22}-Q_{12}\right)<0 \\
& \frac{\partial w_{2}}{\partial G_{2}}=\frac{1}{\Delta}\left[-Q_{22} w_{2}-L s_{R}^{1}\left(Q_{11} Q_{22}-Q_{12}^{2}\right)\right]>0 .{ }^{13}
\end{aligned}
$$

The first term of $\partial Q / \partial G$ is simply the loss of the marginal product of a type 2 worker transferred from private employment to public employment. But if he is worth his wage in the public job, there is no loss to society. The GNP outcome therefore depends on the second term, which has the sign of $\left(s_{R}^{2} /-s_{R}^{1}\right)-R$. As we have argued above, GNP will increase-and weighted unemployment will decrease-if the slope of the NAIRU locus is in absolute value bigger than the relative wage $R$.

In order to provide a concrete example and, subsequently, to give some rough estimates for our findings, we have used the Cobb-Douglas and constant-elasticity-of-substitution production functions as specific forms for the production function. Define $\sigma$ as the elasticity of substitution between the two types of workers: $\sigma=1$ is the Cobb-Douglas case. It will be convenient to define a term $D$, equal to the determinant $\Delta$ divided by $s_{R}^{1} L\left(R Q_{22}-Q_{12}\right)$. This term is positive and, with the CES production function, it is given by

$$
D=\frac{N_{2} \sigma}{L R\left(-s_{R}^{1}\right)}+\frac{N_{2}}{N_{1}}+\frac{s_{R}^{2}}{-s_{R}^{1}} .
$$

The impact of direct job creation (a change in $G_{2}$ ) on GNP is then (from equation 18) given by

$$
\frac{d G N P}{d G_{2}}=\frac{w_{2}}{D}\left(\frac{s_{R}^{2}}{-s_{R}^{1}}-R\right) .
$$

Inclusion of the production side of the model allows us not only to find the impact of a change in $G_{2}$ on GNP, but also to give specific expressions for the impact of $G_{2}$ on adult and teenage unemployment. In other words,

13. The inequalities above imply that $Q_{11} Q_{22}>Q_{12}^{2}$. 
we can evaluate (at least for small changes) the movements around the equilibrium locus achieved for a given magnitude of government employment. ${ }^{14}$ These are given by

$$
\frac{d L_{2} U_{2}}{d G_{2}}=\frac{s_{R}^{2} / s_{R}^{1}}{D}<0, \frac{d L_{1} U_{1}}{d G_{2}}=\frac{1}{D}>0,
$$

so that

$$
\frac{d L U}{d G_{2}}=\left[\left(s_{R}^{2} / s_{R}^{1}\right)+1\right] / D
$$

Consider the interpretation of the conditions 21. The expression of $D$, equation 19 , has three terms, all of them positive. If the first two terms were zero, then hiring one teenager into public employment $\left(d G_{2}=1\right)$ would reduce the number of teenagers unemployed by one $\left(d L_{2} U_{2} / d G_{2}\right.$ goes to unity in this case). The increase in the number of adult unemployed would be $s_{R}^{1} /-s_{R}^{2}$-that is, the reciprocal of the slope of the NAIRU locus. This is just enough to keep the economy in equilibrium. Since the first two terms of 19 are not in fact zero, the overall impact of an increase in $G_{2}$ is scaled down. There are two reasons in the model why hiring one teenager into a directly created job reduces teenage unemployment by less than one. First, as was discussed earlier, the rise in the teenage relative wage causes employers to substitute adults for teenagers at the margin. The measure of this is the term $N_{2} \sigma / L R\left(-S_{R}^{1}\right)$.

Second, to achieve the increase in adult unemployment that is required in order that the economy remain on the NAIRU locus after the increase in $G_{2}$, private output $Q$ must be reduced. ${ }^{15}$ The reduction of $Q$ has the side effect of reducing $N_{2}$ as well as $N_{1}$. In the example of the CES production function, the adjustment of $N_{2}$ and $N_{1}$ at the margin, following the change in $Q$, occurs in the same proportions as the proportions on average $-N_{2} / N_{1}$.

In order to provide some orders of magnitude for the impact of direct job creation, estimates of the parameters can be inserted into equations 20 and 21. Values for $N_{1}, N_{2}$, and $L_{1}$, and $L_{2}$ are taken from data for

14. Since $L_{i} U_{i}=L s^{i}(R)$, it follows that $d L_{i} U_{i} / d G_{2}$ is $L s_{R}^{i} d R / d G_{2}$, which can be found easily from equation 17.

15. This reduction of $Q$ occurs either by demand-management policies or by price-level adjustment. The change in $Q$ must be large enough first to overcome the tendency to increase $N_{1}$ generated by the substitution effect described above, and then further to reduce $N_{1}$. Adult unemployment must end up higher. 
$1974 .{ }^{16}$ Two values of the locus slope $s_{R}^{2} /-s_{R}^{1}$ have been tried-3.05 and 6.1 -and results for both of these values are given. The value 3.05 is Perry's estimate of $R$; it is selected to illustrate the case in which GNP is unaffected. The value 6.1 is simply twice 3.05. Two values of $\sigma$ are used, $\sigma=0.5$ and $\sigma=1.0$; higher substitution elasticity seems unlikely. In addition to the ratio of the $s$, we need an estimate for $s_{R}^{1}$, which appears in $D$. We know of no hard evidence on this parameter. ${ }^{17}$ One way of expressing $s_{R}^{1}$ is to ask: if the adult relative wage fell by 10 percent, how much would the adult unemployment rate have to rise to maintain equilibrium? We experiment with two answers. The first is 10 percent alsofor example, from 4.5 percent to 4.95 percent. The second is 5 percentfor example, from 4.5 percent to 4.73 percent.

Table 1 shows, for different parameter values, answers to the following questions: if 100 teenagers are hired into directly created jobs, how much does (1) teenage unemployment (in persons) fall? (2) total unemployment fall? (3) GNP rise? The range of outcomes is wide. The table indicates how changes in values of strategic parameters affect the outcome, but where the actual parameter values lie cannot be known without difficult empirical research.

Variations in the two labor forces, $L_{1}$ and $L_{2}$, were ignored in the analysis. Changes in these variables will not affect the locus of sustainable combinations of $U_{1}$ and $U_{2}$. However, an increase in $L_{2}$ induced by the lower $U_{2}$ and higher relative wage of this group will make the reduction in its measured unemployment smaller than that derived above. At the same time, the production outcome $Q$ will be more favorable on this account: some of the induced entrants will be employed. Some new entrants will be drawn from the ranks of the discouraged workers or the actually or potentially delinquent. Even if they were not previously counted as unemployed, it is desirable to enable them to work.

Induced reductions in $L_{1}$ are likely to be small, and hence to reduce $Q$ only slightly.

16. From Employment and Training Report of the President, 1976 (Government Printing Office, 1976).

17. Robert E. Hall, "The Process of Inflation in the Labor Market," $B P E A$, $2: 1974$, pp. 343-93, discusses the process by which equilibrium levels of scale wages are restored through changes in rates of wage increase. Michael L. Wachter, in his paper in this issue, gives data showing how relative wage incomes of certain cohorts have changed. If these data are compared with unemployment-rate data that suggest persistent changes in relative unemployment rates for these same groups, the overall picture is consistent with our story-although we make no claim that it proves it. 
Table 1. Effect on Unemployment and Gross National Product of Hiring 100 Teenagers into Public Jobs

Unemployment in persons; GNP in thousands of dollars

\begin{tabular}{ccc} 
Change in unemployment & \multicolumn{2}{c}{ Relative-wage responsiveness } \\
and GNP & $\begin{array}{c}\text { High value } \\
(10 \%-10 \%)\end{array}$ & $\begin{array}{c}\text { Low value } \\
(10 \%-5 \%)\end{array}$ \\
\hline Fall in unemployment & $\sigma=0.5 ;$ NAIRU locus slope $=3.05$ \\
Teenage & 73.4 & 59.1 \\
Total & 49.4 & 39.7 \\
Rise in GNPb & 0 & 0 \\
& $\sigma=1.0 ;$ NAIRU locus slope $=3.05$ \\
Fall in unemployment & & \\
Teenage & 59.1 & 42.5 \\
Total & 39.7 & 28.5 \\
Rise in GNPb & 0 & 0 \\
& $\sigma=0.5 ;$ NAIRU locus slope $=6.1$ \\
Fall in unemployment & & \\
Teenage & 84.7 & 62.3 \\
Total & 70.8 & 139.3 \\
Rise in GNPb & 158.8 & 111.8 \\
& $\sigma=1.0 ;$ NAIRU locus slope $=6.1$ \\
Fall in unemployment & & \\
Teenage & 74.3 & 62.6 \\
Total & 139.3 & 49.9 \\
Rise in GNPb & &
\end{tabular}

Source: Based on text equations 20 and 21. See accompanying text discussion, where the symbols are defined.

a. Assumes that the adult relative wage falls by 10 percent. For the high value, the adult unemployment rate rises 10 percent; for the low value, 5 percent.

b. GNP calculations assume that the teenage wage is $\$ 2.50$ an hour and that teenagers work 1,500 hours per year. If the same is true in directly created jobs, then, ignoring overhead, the budgetary cost of 100 such jobs is $\$ 375,000$.

\section{Wage Subsidies and the NAIRU}

The idea of paying a wage subsidy to increase employment has been around for a long time. Recently, renewed interest has centered on two main forms. First, temporary but general wage subsidies have been proposed as a remedy for high unemployment, possibly confined to incremental hiring. The second, the one considered here, is a selective wage subsidy limited to particular categories of workers. For example, Feldstein has suggested giving to all teenagers vouchers that could be used 
either for schooling or to subsidize employers who hire them. ${ }^{18}$ The Orcutts have recently proposed a wage subsidy payable to all persons who, during the preceding twelve months, have been unemployed for more than some stated amount of time. ${ }^{19}$

Feldstein's proposal fits our analysis, since it is intended to improve the position of a particular demographic group. The Orcutts' proposal is not covered under any of the classifications listed earlier. It would presumably give the most assistance to those with the highest unemployment rates, whatever their demographic group. In Phillips-curve terms, the argument must be that the disadvantaged-defined by high incidence of unemployment in the preceding period-exert less restraint on wages. This is probably true, although a counterargument is that persons who have been unemployed a long time are more anxious to find new jobs and more willing to accept a low wage. ${ }^{20}$

Whatever the details of particular proposals, we should like to consider a wage-subsidy scheme that benefits the same "group 2" workers as direct job creation was assumed to do, applying the apparatus used earlier to analyze the impact of a wage subsidy on the NAIRU. The basic assumption is that expressed in equation 16. A subsidy is used to change the relative wage paid by employers for the two types of labor. Let $\beta$ be the policy variable such that $\beta w_{2}$ is the real wage paid by employers for group 2 workers, where the subsidy implies $\beta<1$. The model used in the previous section remains valid with $\beta w_{2}$ substituted for $w_{2}$ in the third part of equation 16.21 The demand-for-labor equations are combined, as before, with the Phillips curves for equation 7. Presumably, it is the relative wage received $R$ that appears in equation 7 rather than the relative

18. Martin S. Feldstein, Lowering the Permanent Rate of Unemployment, A Study for the Joint Economic Committee, 93:1 (GPO, 1973).

19. Guy Orcutt and Geil Orcutt, "A Proposal to Increase Employment" (Yale University, February 1977; processed).

20. There is even some evidence to support this-at least the acceptance-wage part; see Hirschel Kasper, "The Asking Price of Labor and the Duration of Unemployment," Review of Economics and Statistics, vol. 49 (May 1967), pp. 165-72. Another potential difficulty with the Orcutt proposal is the "moral hazard": it is difficult and costly to determine whether someone is really looking for work or is out of the labor force. In addition, firms would have an incentive to concentrate temporary layoffs on a small group of workers (even more than they already do) rather than spreading the burden more evenly (by short-term plant closings, for example). By this means, some workers will build up eligibility for the subsidy.

21. We will continue to define $R$ as $W_{1} / W_{2}$-that is, the relative wage received. Thus $w_{1}$, the real wage for group 1 , is still equal to $R w_{2}$. 
wage paid $R / \beta .^{22}$ Lowering $\beta$ has an impact on the NAIRU that can be analyzed in a manner similar to the analysis of direct job creation. In the case of a CES production function, the outcome of the wage subsidy is quite closely related to the outcome of direct job creation:

$$
\begin{array}{r}
-\frac{d G N P}{d \beta}=\frac{w_{2} N_{2} \sigma}{D}\left(\frac{s_{R}^{2}}{-s_{R}^{1}}-R\right) ; \frac{d L_{1} U_{1}}{d \beta}=\frac{-N_{2} \sigma}{D} ; \\
\frac{d L_{2} U_{2}}{d \beta}=\frac{N_{2} \sigma}{D} \frac{s_{R}^{2}}{\left(-s_{R}^{1}\right)} ; \frac{d L U}{d \beta}=\frac{N_{2} \sigma}{D}\left(\frac{s_{R}^{2}}{-s_{R}^{1}}-1\right),
\end{array}
$$

where the derivatives are evaluated starting from $\beta=1$. They are simply $N_{2} \sigma$ times the corresponding derivatives from direct job creation. The counterpart of $d G_{2}$ is $N_{2} \sigma(-d \beta)$, the number of additional teenagers hired on the first round as a result of a wage subsidy of $-d \beta$. Subsequent adjustments to maintain NAIRU equilibrium are the same in both cases.

The working of the wage subsidy is illustrated in figure 3 , which is analogous to figure 2. As before, the locus $C B A$ gives the combinations of adult and teenage unemployment that equilibrate both labor markets. Each point on the locus is associated with a relative wage, with higher values of $R$ occurring at points further to the southeast. Point $E$ represents the demographic mix of government employment; $E A$ gives the path of total private and public employment for various levels of real private output at a given relative wage paid by employers. The slope of the path depends upon this relative wage paid; the path $E A$ is drawn for the wage $R^{0}$ that corresponds to point $A$ on the NAIRU locus. If a wage subsidy $\beta$ is introduced and the relative wage received remains $R^{0}$, then the relative wage paid by firms is $R^{0} / \beta$ and the path $E A$ shifts to $E C$. But $R^{0}$ is no longer consistent with stability when the unemployment combination is $C$ instead of $A$. The relative wage received decreases $\left(W_{2}\right.$ rises relative to $W_{1}$ ) and the employment path rotates clockwise to $E B$. In the new equilibrium (that is, in $C$ as compared to the original $A$ ), (1) the relative wage paid by employers is higher; (2) the relative wage received is lower (teenagers get relatively more and firms pay relatively less, the gap being the subsidy); (3) teenage unemployment is lower, adult unemployment is higher, and the unemployment count is lower.

22. Workers presumably respond to $R$ in their search and turnover behavior and firms know this when they set wage offers. Note, however, that we do not assume $R$ remains constant. A wage subsidy for teenagers would increase the demand for teenagers and change the equilibrium $R$-that is part of the process described below. 


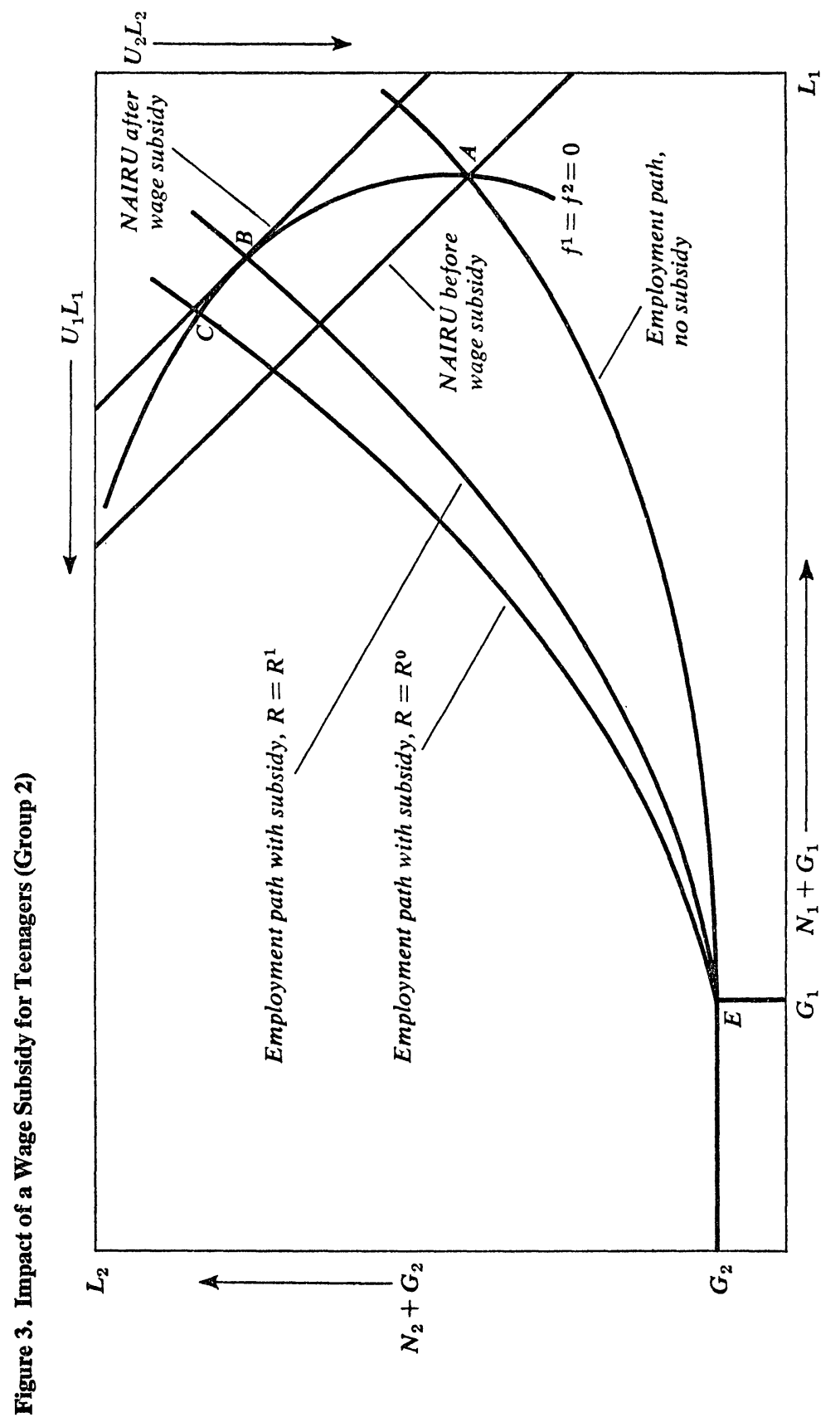


The figures given in table 1 also illustrate the impact of a wage subsidy of the same total budget cost as direct job creation. If a CES function with elasticity $\sigma$ is assumed, a wage subsidy is $\sigma$ times as effective per dollar as direct job creation. Thus, if $\sigma=0.5$, the figures given for direct job creation in table 1 should be reduced by one-half to give the effect of the same expenditure on a wage subsidy. The two policies are equivalent in this sense if $\sigma=1$ (Cobb-Douglas).

Effectiveness per budget dollar is only one consideration in comparison of direct job creation and wage subsidy. More important is an evaluation of output resulting from direct job creation relative to that from increased private employment. Another dimension is the possible political resistance of unions to a wage subsidy paid to private employers.

\section{THE SHORT-RUN TRADEOFF}

Currently, direct job creation is proposed as an instrument of short-run fiscal policy, as part of a package to stimulate economic recovery. How does the short-run impact of direct job creation differ from the long-run results obtained above?

If $\dot{W}_{1}$ and $\dot{W}_{2}$ are given by equation 7 , then the overall rate of wage inflation $\dot{W}$ is given by

$$
\dot{W}=\theta_{1} f^{1}+\theta_{2} f^{2}+\text { feedback terms, }
$$

where $\theta_{1}$ and $\theta_{2}$ are the payroll shares. If one concentrates employment gains (unemployment reductions) on group 2 workers, under what conditions can one (a) lower overall unemployment, $U=\alpha_{1} U_{1}+\alpha_{2} U_{2}$, in the short run and keep $\dot{W}$ constant (in other words, improve the shortrun Phillips curve); and (b) raise GNP (which implies lowering wageweighted unemployment, $R \alpha_{1} U_{1}+\alpha_{2} U_{2}$ ) in the short run and keep $\dot{W}$ constant?

For our purposes "short run" involves holding the relative wage $\boldsymbol{R}$ constant and the feedback terms constant. Cross-unemployment effects will also be ignored. If $\dot{W}$ is held constant this gives

$$
d \dot{W}=\theta_{1} f_{1}^{1} d\left(\alpha_{1} U_{1}\right)+\theta_{2} f_{2}^{2} d\left(\alpha_{2} U_{2}\right) .
$$

The change in overall unemployment is simply

$$
d U=d\left(\alpha_{1} U_{1}\right)+d\left(\alpha_{2} U_{2}\right) .
$$


The short-run Phillips curve is then improved by programs for group 2 workers provided that

$$
-\theta_{1} f_{1}^{1}>-\theta_{2} f_{2}^{2} \text {. }
$$

This is a weaker condition than those for long-run improvement, since it does not involve relative-wage effects.

The change in wage-weighted unemployment is

$$
d U_{w}=R d\left(\alpha_{1} U_{1}\right)+d\left(\alpha_{2} U_{2}\right) .
$$

Since it is approximately true that $R \theta_{2} / \theta_{1}=\alpha_{2} / \alpha_{1}$, it follows that a noninflationary short-run gain in GNP can be made provided that

$$
-\alpha_{1} f_{1}^{1}>-\alpha_{2} f_{2}^{2} \text {. }
$$

Recall that $f^{1}$ and $f^{2}$ are defined as functions of $\alpha_{1} U_{1}$ and $\alpha_{2} U_{2}$. Thus 28 is simply the condition that the Phillips curve for adults (defined with respect to $U_{1}$ ) be steeper than the Phillips curve for teenagers (defined with respect to $\left.U_{2}\right) .^{23}$

\section{Empirical Evidence}

The possibilities of "cheating the Phillips curve" by direct job creation, selective wage subsidies, or other labor-market policies, depend, according to the theories presented in previous sections, on three hypotheses: (1) Vacancies are, independently of unemployment rates, important for wage inflation. (2) Primary unemployment-of adult males or of all adults-is relatively more important for wage behavior than unemployment of other workers. (3) Relative-wage levels affect adjustments of wages in specific markets or industries.

We have attempted some econometric calculations bearing on these propositions, and we present some of them in this section. Our confidence in these results is limited.

23. Lags in the wage equations will affect short-run outcomes. In econometric Phillips curves the unemployment variable is often a distributed lag. For long-run analysis the lags do not matter. But the relevant lag distribution on $U_{1}$ may differ from that on $U_{2}$, perhaps because wage contracts are more important in labor markets for adults. Even if the Phillips curve for teenagers is fundamentally flatter than that for adults, this may not translate into improvement in the short-run tradeoff if the wage effects of unemployment of teenagers occur with shorter lags. 


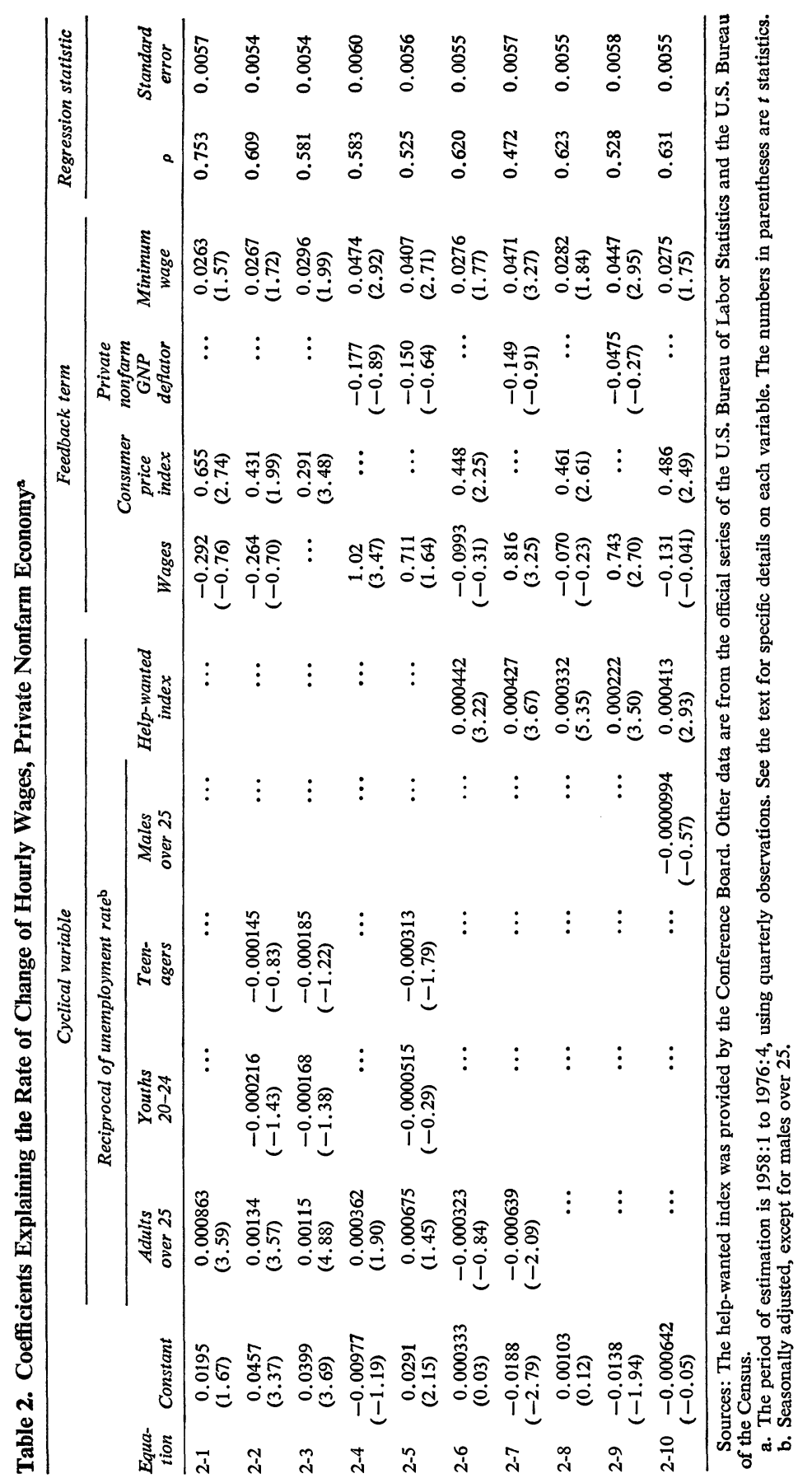


In table 2 we report several alternative regressions "explaining" economy-wide inflation. The observations are quarterly, spanning 1958 through 1976. The dependent variable is the four-quarter proportional rate of change of private nonfarm hourly wage rates. The explanatory variables are of three types: The first are reciprocals of unemployment rates for demographic groups, adjusted for the relative size of the groups in the overall labor force. The variable is entered as a four-quarter average, lagged one quarter behind the dependent variable. The groups used were adults over twenty-five, youths twenty to twenty-four, and teenagers. An additional regression uses the unadjusted rate for males over twentyfive, a popular variable in other studies. The second set of explanatory variables was the help-wanted index published by the Conference Board, deflated by total employment. A linear four-quarter average lagged one quarter is used. The third set were wage and price feedback variables. In all cases the variables used were averages of the four-quarter proportional rates of change. The averages were for eight quarters, lagged one quarter. The wage itself, the consumer price index, and the deflator for private nonfarm GNP were used.

Partly on theoretical grounds and partly based on Gramlich's findings, the four-quarter proportional rate of change of the legal minimum wage is included as a feedback variable. ${ }^{24}$ It is not averaged but is lagged one quarter. It enters with a very small coefficient and is intermittently significant.

The macroeconomic wage regressions of table 2 support the proposition that vacancies, via their proxy, the help-wanted index, are important. Indeed, as a measure of labor-market tightness, this demand-side variable appears to be stronger than unemployment rates. Equation 2-10 of table 2 attributes a stronger effect to the index than to the reciprocal of the unadjusted unemployment rate for males over twenty-five. ${ }^{25}$

So far as the adjusted unemployment rates are concerned, the regressions confirm the differential importance of primary unemployment. Indeed, the secondary rates are insignificant and their coefficients have the wrong sign. Doubtless, collinearity is part of the reason why it is

24. Edward M. Gramlich, "Impact of Minimum Wages on Other Wages, Employment, and Family Incomes," $B P E A, 2: 1976$, pp. 409-51.

25. We make no claim that the help-wanted index explains the shifting Phillips curve. "Other factors" may have caused trends in the index that are correlated with the inflationary spurt of the 1970 s. Our purpose is just to show that vacancies matter. 
difficult to estimate the relative importance of several unemployment rates in wage behavior.

Partly to see how well the findings of the aggregate wage equations held up at a slightly lower level of aggregation, and partly to test the importance of relative-wage levels, various Phillips curves were estimated for wages in seven major sectors. The results are shown in table $3 .^{28}$

The same adjusted unemployment rates and deflated help-wanted index were used as in the aggregate wage equations. Of the feedback variables, only the two price indexes and the minimum wage were used. Experiments with wage feedbacks, both sector own wage and aggregate wage, were not encouraging. Collinearity was a severe problem. We concluded that wage-feedback terms were not so appropriate in sectoral equations including relative-wage levels. In practice, the wage-feedback variables generally reduced the significance of the relative wage. ${ }^{27}$

The relative-wage variable is important in specification of the sectoral equations. The hypothesis used in the theoretical analysis was that a rise in the wage of a sector relative to other wages would reduce the rate of increase of the sector's wage. A variable defined as the ratio of the sector's wage to the index of private nonfarm wages was included as a moving average from $t-1$ to $t-8$. The results are reported in column 9 of table 3. The hypothesis receives rather strong empirical support. For the six sectors excluding construction, there are sixteen equations with the expected sign and two with perverse signs-neither significantly positive. Many of the negative signs are significant. Even including construction, the sign count is sixteen to five. Such a consistent pattern would be unlikely if the true coefficient were zero or positive. Construction wages behaved in a notoriously unpredictable way over the period. The finding that construction workers, having achieved a high relative wage, were induced to bargain for even larger wage increases is not inconsistent with anecdotal evidence about the industry.

The hypothesis that unemployment among older adults (column 2) is more important as a determinant of wage inflation than the unemployment

26. The sectors are manufacturing; wholesale and retail trade; services; mining; transportation; construction; finance, insurance, and real estate. The wage data are from Employment and Earnings, various issues. More complete results, matching those of table 2, are available from the authors.

27. An exception is the construction industry, in which wage feedbacks turned perverse signs on relative wages into expected negative coefficients, some significant. 
among youths and teenages (columns 3 and 4 ) is generally confirmed by the sectoral equations.

The superiority of the deflated help-wanted index as a measure of labor-market tightness is supported by the manufacturing, transportation, and mining equations, but not by the other sectoral equations.

The coefficient of the minimum-wage variable, though generally small, continued to be both significant and robust across specifications. The service sector was the only one with consistently perverse negative signs. It is not unreasonable that an increase in the minimum wage would throw workers into the service sector, causing a downward pressure on wages there. The coefficients and statistical significance of the minimum-wage variable in finance, insurance, and real estate seem too good to be true. There are other odd features of this sector-the relative-wage variable has an incorrect sign, for example.

Our general conclusion from the regressions is that the hypotheses necessary for success of direct job creation, wage subsidies, and kindred policies are empirically supported, at least qualitatively. But our previous analysis makes us skeptical of the more extravagant hopes and claims for these policies, especially in the long run. Gains in GNP are harder to come by than reduction in unemployment counts. In the long run, displacements of workers from private employment, both in and outside the target population, will offset some of the direct employment gains. A large share of the case for direct job creation or selective subsidies depends on important effects not captured in aggregate measures of employment and production: improved distribution of income and opportunity. 


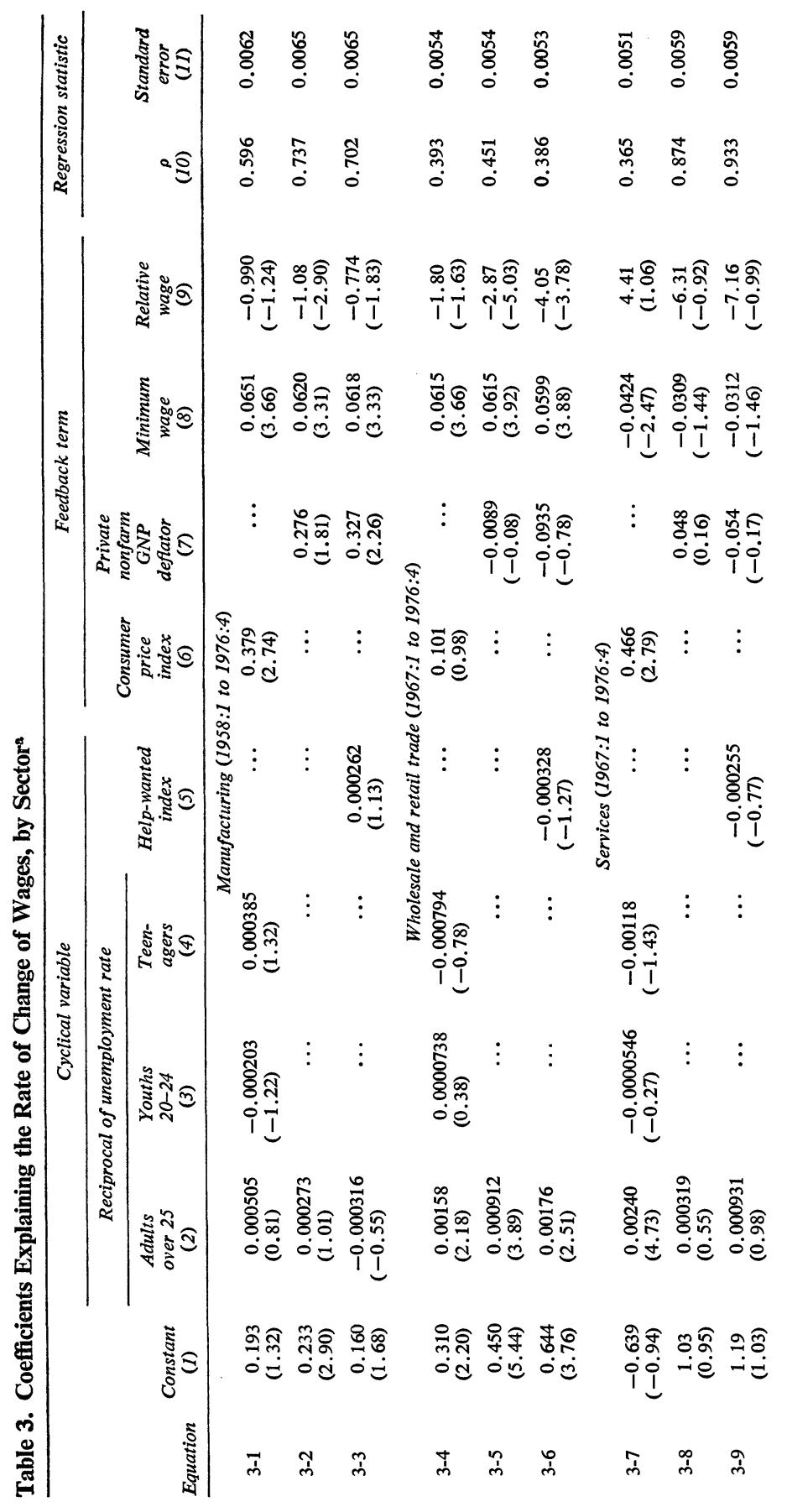




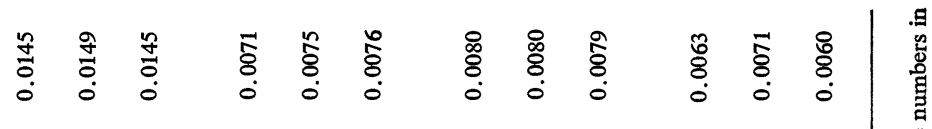

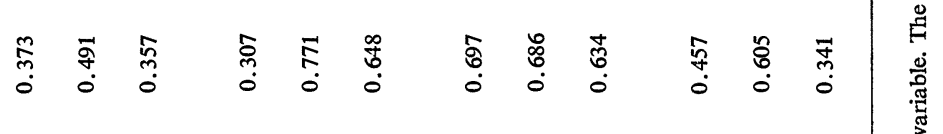

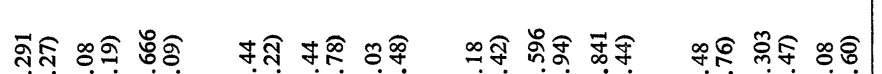

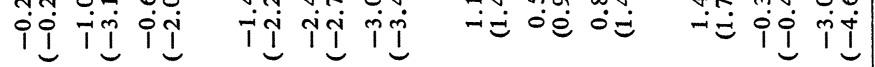

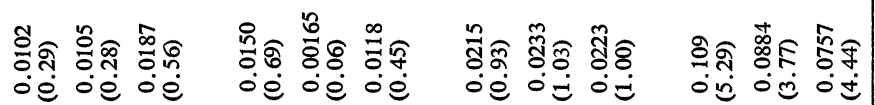

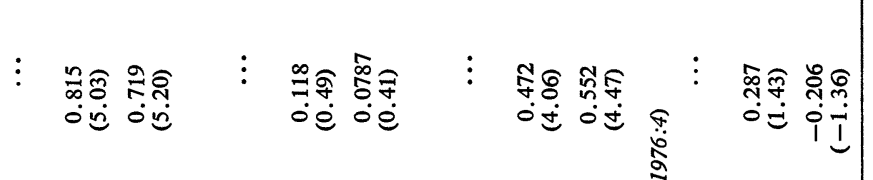

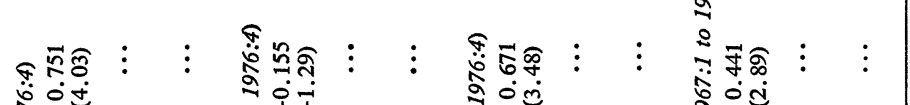

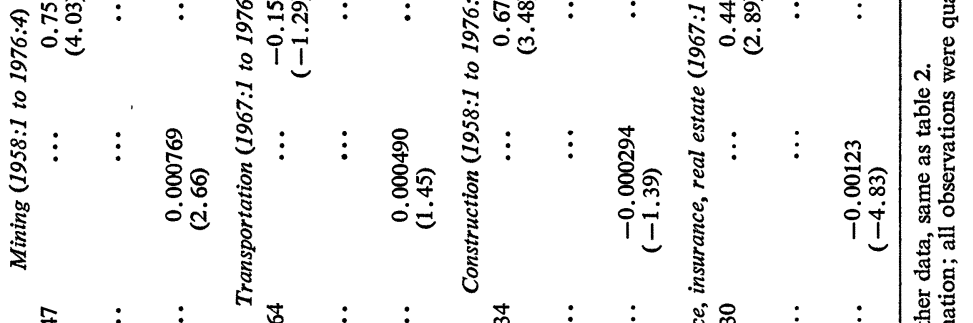

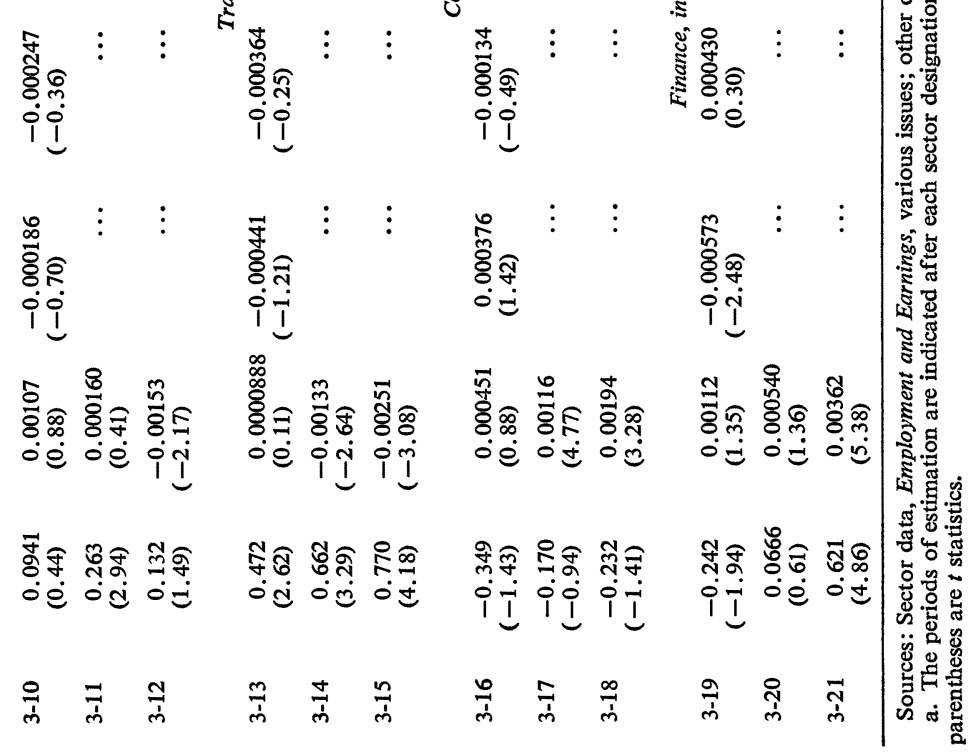




\section{Discussion}

Charles holt and Michael Wachter complimented the authors for making an important analytic contribution to an area of crucial social importance that has not been sufficiently explored. As Wachter interpreted the main thrust of the paper, he concluded that direct job creation shifted the burden of unemployment from one group to another. Its effectiveness depended upon the relative slopes of the group Phillips curves. If teenagers had a sufficiently flat Phillips curve, the overall NAIRU would be lowered by shifting employment toward them, but still at some cost in higher unemployment of adults.

In response to a question, James Tobin reviewed the conditions under which the wage-weighted unemployment rate would not fall even though a conventional unemployment rate that counted the number of persons was reduced. If one adult was a perfect substitute for three teenagers, replacing an adult with three teenagers would do nothing for wage-weighted unemployment or real GNP but would reduce the number of people unemployed. Tobin noted that such a shift might be deemed socially desirable for reasons such as income distribution and human capital, a point endorsed by Thomas Juster. Benjamin Friedman suggested, however, that taking into account the dependents of workers might lead to a social preference for jobs for adults.

There was some discussion of the relative effects on wage inflation of hiring teenagers and adults. Tobin argued that the relative wage weights gave no clear guide to the relative inflation effects. If adult wages are three times those of teenagers, employing three teenagers would not necessarily have the same total inflationary impact as hiring a single adult. He saw reasons to believe that the former would be less inflationary. George Perry said that some of the institutional barriers to employment of teenagers, such as minimum wages, might reduce the wage response from hiring teenagers, thus tilting the balance in the direction suggested by the paper.

Robert Hall was concerned that the entire analysis rested on the response of the relative natural unemployment rates of the two demographic groups to their relative wages. He knew of no evidence at all that bore on this issue. He thought the authors' conclusions could be established in a 
way that was less dependent on their particular model. He was skeptical of that model because it assumed that the widely different unemployment rates observed among teenagers and adults at full employment represented an equilibrium-not a differential excess supply of teenagers. Hall saw evidence that there was excess supply. Contrary to popular notions, he contended that less than one out of ten unemployed teenagers become unemployed by quitting; about half the teenage unemployed have never held a job; more than half have permanently left school and are looking for full-time work. Hall inferred a serious and chronic shortage of jobs for those teenagers willing to work at the prevailing wage. He suspected that legal barriers to market equilibrium played a major role. These included the minimum wage, but also various "fair labor" legal provisions of equal pay for all who perform the same job. If the wage for teenagers is kept artificially high by such legal arrangements, direct job creation will not raise it appreciably. The paper's conclusions will thus stand, but for reasons quite different from those the authors had implied.

Arthur Okun countered that high turnover provided an adequate explanation of high teenage unemployment in equilibrium. Hall's own papers on turnover were persuasive to him. It was greater frequency of spells, not longer duration, that swelled the unemployment rate for teenagers relative to that for adults. The pool of unemployed relative to the monthly flow into jobs was smaller for teenagers than for adults. Okun also cited Wachter's findings that wages in low-paid jobs rose more rapidly than those in higher-paid jobs during cyclical upswings (although he conceded that differential lags may affect that result). On the whole, Okun cautioned against concluding that the Phillips curve for teenagers was very flat.

Several participants discussed ways of dealing with the teenage unemployment problem. Martin Feldstein emphasized ensuring that jobs provided skills and training and not simply employment. Lower minimum wages would allow employers to spend more money on training teenagers. James Duesenberry observed, on the other hand, that low-wage jobs generally had only a small training component; he doubted that a lowering of the minimum wage would do much to encourage training. Juster cautioned that it was difficult to distinguish operationally between jobs that provided skills and those that did not. The counter clerk at McDonald's might later become an assistant manager. Robert J. Gordon noted that the most serious problem affected black teenagers. Jobs were often available 
in the suburbs, but not the ghettoes. It was not just a matter of subsidizing jobs, but of locating them close to those that need them.

Gordon noted that the increased share of teenagers in the labor force in the past two decades provided evidence of how markets adjusted. In principle, the increased share could reduce relative wages of teenagers or raise their unemployment rates. His own work suggested that the effects were split approximately 50-50; that was consistent with the Baily-Tobin model, in which the relative wage has some, but not perfect, flexibility. Gordon suspected that the minimum wage held down the degree of flexibility substantially. 